\title{
Increased concentrations of interleukin $1 \beta$, interleukin-2, and soluble interleukin-2 receptors in endoscopical mucosal biopsy specimens with active inflammatory bowel disease
}

\author{
J Brynskov, N Tvede, C B Andersen, M Vilien
}

\begin{abstract}
Concentrations of interleukin-1 $\beta$ (IL-1 $\beta$ ), interleukin-2 (IL-2), and soluble IL-2 receptors (sIL-2R) were determined by enzyme linked immunosorbent assays (ELISA) in supernatants of sonicated endoscopical mucosal biopsy specimens from 31 patients with inflammatory bowel disease and 19 controls. IL- $1 \beta$ was detected in $53 \%$ of the patient supernatants $(p=0.0001)$, IL-2 in $35 \%$ $(p=0.0031)$, compared with none of the controls. Soluble IL-2R was present in $55 \%$ and $26 \%$ of the specimens, respectively $(p=0.07)$. The concentrations of IL- $1 \beta(p=0.00015)$, IL-2 $(p=0.0019)$, and sIL-2R $(p=0.0073)$ were highest in the most inflamed biopsy specimens, compared with less inflamed specimens and controls. There were no significant differences in IL-1 $\beta, I L-2$, and sIL-2R concentrations between ulcerative colitis (16) and Crohn's disease patients (15). The results suggest that enhanced cellular immunity operates in vivo at the mucosal level in active inflammatory bowel disease.
\end{abstract}

$T$ cell proliferation and differentiation depend on the interplay between interleukin-2 (IL-2) production and IL-2 receptor (IL-2R) expression. ${ }^{1}$ Increased circulating concentrations of IL- ${ }^{2}$ and soluble form of IL-2R (sIL-2R) have recently been shown in vivo in active inflammatory bowel disease using enzyme linked immunosorbent assays (ELISA). ${ }^{2-4}$ At the gut level, the IL-2 dependent pathway of immune activation has largely been studied in vitro using mononuclear cells isolated from surgical specimens which often represent end pathological states. ${ }^{56}$

The advent of specific ELISAs has facilitated the measurement of cytokines in small volumes $(50-100 \mu \mathrm{l})$. Therefore, it seemed of interest to determine the mucosal concentrations of IL-2 and sIL-2R, using ELISAs, as markers of in vivo $T$ cell activation in endoscopical biopsy specimens from patients with less advanced inflammatory bowel disease. Because the initiation of a $T$ cell response is facilitated by interleukin-1 (IL-1) (a family of polypeptides produced primarily by antigen presenting cells), ${ }^{7}$ the content of IL- $1 \beta$ was also measured.

\section{Methods}

PATIENTS

Mucosal biopsy specimens were obtained at colonoscopy (or coloileoscopy) from 31 consecutive inflammatory bowel disease patients (19 women and 12 men) with suspected activity. Median age was 40 years (range 18-73) and the disease time three years (range 0-32). Sixteen patients had ulcerative colitis ${ }^{8}$ and 15 Crohn's disease' (seven ileocolonic, five colonic, and three small bowel disease). The biopsy specimens were taken by standard colonoscopy biopsy forceps and preferably obtained from inflamed mucosa. The material consisted of 27 colon (seven proctosigmoid) and four small bowel mucosal biopsy specimens. Only one biopsy specimen from each patient was included.

Clinical activity was measured on a semiquantitative scale ${ }^{10}$ of: I (inactive), II (slightly active), III (moderately active), and IV (very active) in ulcerative colitis patients (median III, range I-IV) and by the Simple Index (SI)" in Crohn's disease patients (median 6, range 1-10). All ulcerative colitis and 10 Crohn's disease patients $(67 \%)$ had clinically active disease (SI $>4)$. Sixteen patients received sulphasalazine treatment (median $3 \mathrm{~g} /$ day, range $2-4$ ), and one oral prednisolone $20 \mathrm{mg} /$ day.

Normal colon tissue was obtained from 19 patients (four women and 15 men) with a median age of 65 years (range 45-83) who underwent control colonoscopy, because of previous polypectomy. None of the patients had cancer of the colon and the biopsies were obtained from macroscopically normal colonic mucosa.

All patients gave informed consent in accordance with the Second Helsinki Declaration.

\section{TISSUE}

Biopsy specimens were immediately embedded in Tissue-Tek (Miles, Indiana, USA), snap frozen in solid ice/2-methyl butane (Merck, Darmstadt, West Germany) mixture and stored at $-70^{\circ} \mathrm{C}$.

Histological examination was carried out blindly without knowledge of the results of the cytokine measurements using a haematoxylineosin stained frozen section of the biopsy specimen. Two of 41 (5\%) originally examined biopsy specimens were excluded because the frozen sections were technically inadequate for histological grading. A further eight specimens (20\%) were excluded, because only deep biopsies containing the muscularis mucosa were considered representative. The histological degree of inflammation was graded according to the criteria of Morson and Dawson ${ }^{12}$ on the following scale: 0 (normal), 1 (slightly active), 2 (moderately active), and 3 (very active). 


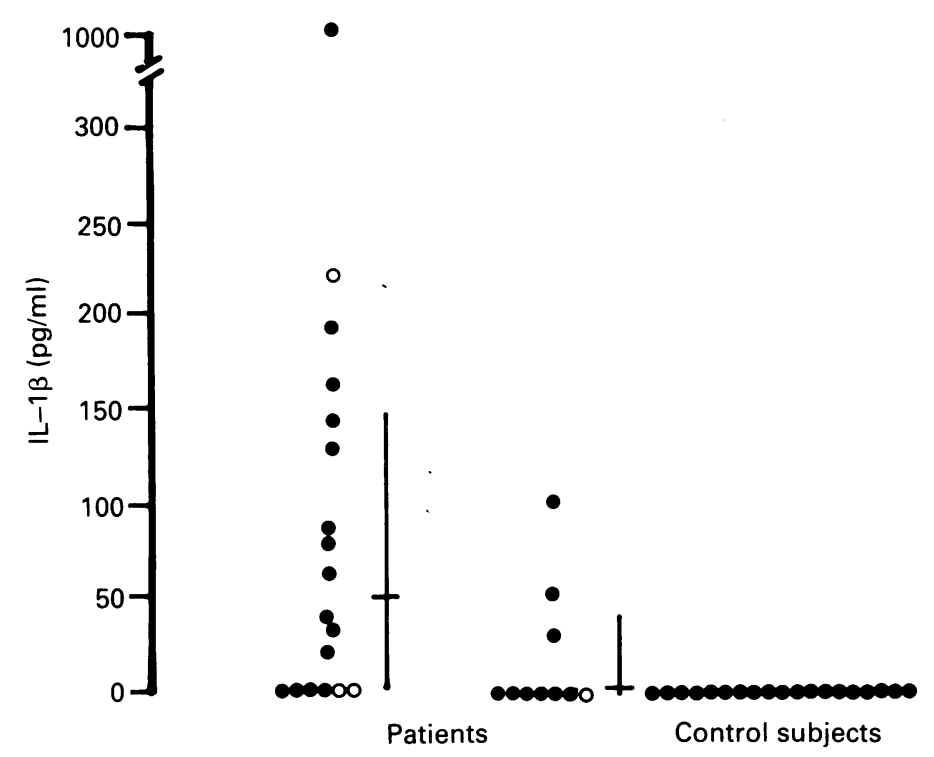

$\overbrace{2-3}^{\text {Histology scale }}$

Figure 1: Interleukin 1ß (IL1-B) concentrations in supernatants of sonicated, endoscopical colon (O) or small bowel (O) mucosal biopsy specimens from patients with inflammatory bowel disease (IBD) and controls. Histological inflammation is graded from 0 (normal) - 3 (very active) Bars represent median and $25-75 \%$ ranges: $p=0.00015$ (Fonckheere-Terpstra test).

\section{SUPERNATANTS}

After thawing, the biopsy specimens were gently rinsed, dried for a few seconds on filter papers, and placed at $0^{\circ} \mathrm{C}$ in polypropylene tubes (Nunc, Roskilde, Denmark) at a concentration of $5 \mathrm{mg}$ tissue $/ \mathrm{ml}$ in $0.5 \%$ human albumin/RPMI 1640 (Gibco, Paisley, UK). After sonication for three minutes using a Branson Sonifier (duty cycle $50 \%$ ) (Vésenaz-Genf, Switzerland), the supernatants were collected by centrifugation $(1800 \mathrm{~g}$, 10 minutes), divided in several aliquots and deep frozen in polypropylene tubes (Nunc).

\section{CYTOKINES}

The amount of IL- $1 \beta$ present in the supernatants were measured using solid-phase ELISA (Interleukin $1 \beta$, Cistron Biotechnology, NJ, USA). Briefly, a monoclonal IL- $1 \beta$ antibody was absorbed onto microtitre plates and supernatant samples were added in duplicates together with known IL-1 $\beta$ standards. Polyclonal rabbit antiIL-1 $\beta$ was used to detect IL-1 $\beta$ bound in the solid phase. Horseradish peroxidase conjugated antirabbit-IgG was added to the test wells and after development of the substrate, the colour intensity was measured using a microtitre plate reader. The amount of IL- $1 \beta$ in each sample was derived from the optical density of the known standards. Previous studies have documented the specificity of this assay for IL- $1 \beta$ and that the sensitivity is equivalent to or better than bioassays. $^{13}$

The amount of IL-2 (Intertest-2, Genzyme Corporation, Boston, MA, USA) and sIL-2R (Cellfree, T Cell Sciences, Cambridge, MA, USA) were determined by solid phase ELISAs as described in detail previously. ${ }^{2}$ The reproducibility of all measurements were within $10 \%$ in our laboratory.
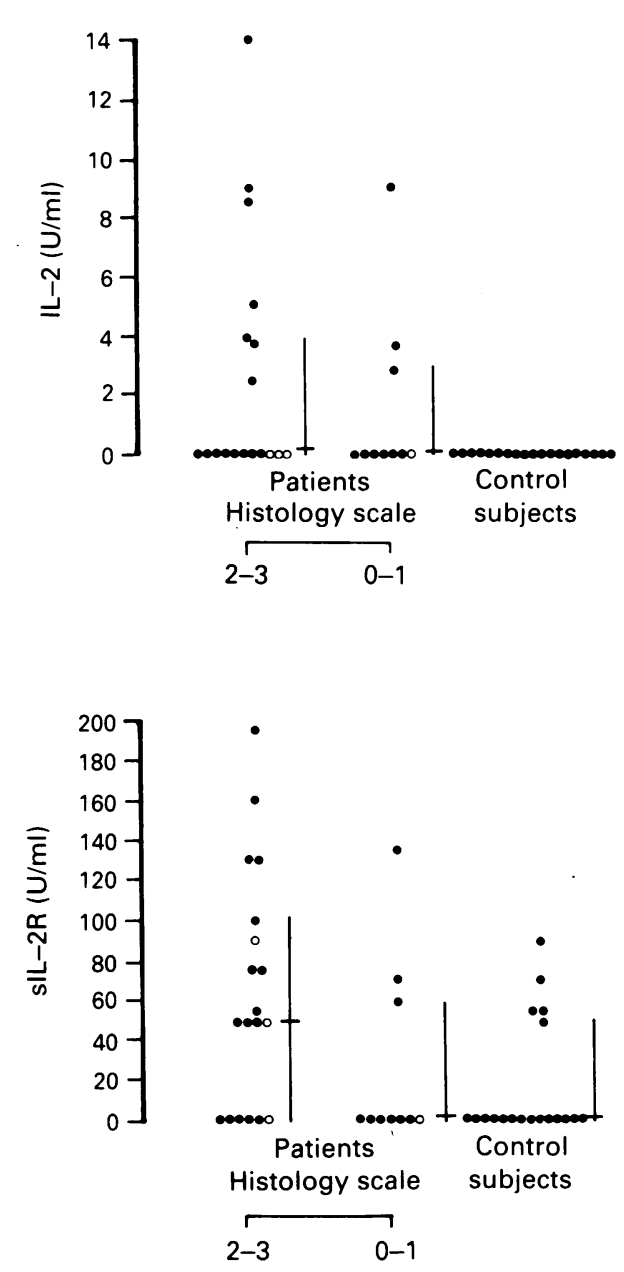

Figure 2: Interleukin 2 (IL-2) (upper) and soluble/shed IL-2 receptor (sIL-2R) concentrations (lower) in supernatants of sonicated, endoscopical colon (O) or small bowel (O) mucosal biopsy specimens from patients with inflammatory bowel disease (IBD) and controls. Histological inflammation is graded from 0 (normal)-3 (very active).

Bars represent median and $25-75 \%$ ranges: $p=0.0019$

(upper; $p=0.0073$ (lower) (Fonckheere-Terpstra test).

test and variance for ordered alternatives by the Jonckheere-Terpstra test; correlations by the Spearman rank order test and outcome ratios by Fisher's test according to Siegel and Castellan. ${ }^{1+}$ Two sided tests were used (except for the Jonckheere-Terpstra test which is one tailed). $\mathrm{p}<0.05$ were considered significant.

\section{Results}

The median histological grade of inflammation in the patient biopsy specimens was 2 (moderately active) (range 0-3). Eight of 19 control specimens showed signs of slight inflammation; the rest were normal.

IL-1 $\beta$ was detected in 15 of $28(53 \%)$ of the patient supernatants studied, compared with none of the controls $(p=0.0001)$. The median IL- $1 \beta$ concentration in patient specimens was 26 $\mathrm{pg} / \mathrm{ml}$ (range $0-1000)(\mathrm{p}=0 \cdot 0002)$. Figure 1 shows that significantly greater amounts of IL$1 \beta$ were present in the most inflamed biopsy specimens (median $48 \mathrm{pg} / \mathrm{ml}$, range 0-1000), compared with less inflamed specimens (median $0 \mathrm{pg} / \mathrm{ml}$, range $0-102$ ) and controls. IL- $\beta$ was present in one of four small bowel biopsy specimens (Fig 1). There was no difference in IL-1ß concentrations between ulcerative colitis 
(median $20 \mathrm{pg} / \mathrm{ml}$, range 0-192) and Crohn's disease patients (median $32 \mathrm{pg} / \mathrm{ml}$, range $0-1000$ ) $(\mathrm{p}=0 \cdot 7)$.

IL-2 was detected in 10 of $28(35 \%)$ of the patient supernatants studied, compared with none of the controls $(p=0.0031)$. The median IL-2 concentration in patient supernatants was $0 \mathrm{U} / \mathrm{ml}$ (range $0-13 \cdot 8)(\mathrm{p}=0 \cdot 004)$. Figure 2 shows that significantly greater amounts of IL-2 were present in the most inflamed biopsy specimens (median $0 \mathrm{U} / \mathrm{ml}$, range $0-13 \cdot 8$ ), compared with less inflamed specimens (median $0 \mathrm{U} / \mathrm{ml}$, range $0-8.9$ ) and controls. None of the small bowel biopsy specimens contained IL-2. There was a tendency towards higher IL-2 concentration in ulcerative colitis (median $2.5 \mathrm{U} / \mathrm{ml}$, range 0-14), compared with Crohn's disease patients (median $0 \mathrm{U} / \mathrm{ml}$, range $0-8.9)(\mathrm{p}=0.07)$.

Soluble IL-2R was detected in 16 of $29(55 \%)$ of the patient supernatants studied, compared with five of 19 controls $(26 \%)$; this difference being only borderline significant $(p=0 \cdot 07)$. The median sIL-2R concentration in patient specimens, however, was increased (median $50 \mathrm{U} / \mathrm{ml}$, 0-195), compared with controls (median $0 \mathrm{U} / \mathrm{ml}$, range $0-90)(p=0.03)$. Figure 2 shows that significantly greater amounts of sIL-2R were present in the most inflamed biopsy specimens (median $50 \mathrm{U} / \mathrm{ml}$, range $0-195$ ), compared with less inflamed specimens (median $0 \mathrm{U} / \mathrm{ml}$, range $0-135$ ) and controls. sIL-2R was present in two of four small bowel biopsy specimens (Fig 2). There was no difference in sIL-2R concentrations between ulcerative colitis (median $50 \mathrm{U} / \mathrm{ml}$, range 0-195) and Crohn's disease patients $(25 \mathrm{U} / \mathrm{ml}$, range $0-160)(\mathrm{p}=0.51)$.

A significant correlation was found only between patient supernatant IL-1B and sIL-2R concentrations $(R(S)=0.505, p=0.012)$. No significant correlations were found between IL-1B, IL-2, or sIL-2R concentrations and clinical activity measures of ulcerative colitis or Crohn's disease.

\section{Discussion}

It was found in this study that endoscopical mucosal biopsy specimens from patients with inflammatory bowel disease contained significantly increased amounts of IL-1B, IL-2, and sIL-2R. Furthermore, the highest concentrations were consistently found in the most inflamed biopsy specimens (Figs 1, 2). The histological grade of inflammation was used as the reference, because clinical (and endoscopical) indices may underestimate the extent of the disease at the tissue level. ${ }^{10}{ }^{15}$ Accordingly, we were unable to show any correlations between clinical activity indices of Crohn's disease or ulcerative colitis and IL-1B, IL-2, or sIL-2R concentrations.

Intestinal immune functions in inflammatory bowel disease have been studied mainly in vitro, using techniques for isolating mucosal cells from surgical specimens. The presently devised method, using ELISAs and endoscopical mucosal biopsy specimens, is simple and facilitates the study of local immune functions in vivo in a broader range of inflammatory bowel disease patients. Furthermore, the effects of surgery, anaesthesia, ongoing intense immunosuppressive treatment, and cell isolation procedure ${ }^{16}$ are to some extent avoided. Longitudinal studies are required to establish whether the determination of mucosal cytokine concentrations also provides a simple means of monitoring disease activity in vivo at the gut level in inflammatory bowel disease, including the effects of medical treatments. It should be noted, however, that even in some of the most inflamed biopsy specimens, cytokine concentrations were zero (Figs 1, 2). This is probably not as a result of technical problems, because the biopsies were taken in a uniform way and strict criteria were applied to include only technically adequate and representative biopsy specimens. Because inflammation may be focally distributed perhaps more than one frozen section should be examined to ensure a representative assessment of the grade of histological inflammation in individual biopsy specimens.

Interleukin 1 production and antigen presentation are involved in $\mathrm{T}$ cell activation, ${ }^{7}$ which leads to IL-2 production and IL-2R expression. ${ }^{1}$ The present demonstration of increased in vivo mucosal concentrations of $I L-1 \beta$ in active inflammatory bowel disease extends to previous in vitro studies on both cultured mucosa ${ }^{17}$ and intestinal mononuclear cells. ${ }^{18}$ In addition to $\mathrm{T}$ (and B) cell activation, IL-1 orchestrates a wide spectrum of immunoinflammatory activities pertinent to inflammatory bowel disease. ${ }^{7}$ Activated macrophages appear to be the major source in the inflamed mucosa, ${ }^{18}$ and our results supports earlier notions that this monokine may play an important role in the pathogenesis of inflammatory bowel disease. ${ }^{17}{ }^{18}$ IL-1 has also recently been shown to be cytotoxic to islet of Langerhans ${ }^{19}$ and cytostatic to thyrocytes, ${ }^{20}$ but it remains to be studied whether a similar cellular effect also operates against mucosal cells in inflammatory bowel disease.

Increased in vivo concentrations of IL-2 have been previously shown by ELISA using plasma samples from patients with active Crohn's disease. ${ }^{2}$ The present demonstration of increased IL-2 concentrations also in mucosal inflammatory bowel disease biopsies extends this observation, although it seems to contrast the conclusions reached in in vitro experiments using bioassay. Here isolated mononuclear cells have been found to produce decreased amounts IL-2, and it has been suggested that deficiency of this essential growth factor may hamper the development of a normal immune response in inflammatory bowel disease. ${ }^{5}$ Mucosal lymphocytes, however, produce high amounts of IL-2 after challenge with a strong antigen unspecific stimulus, ${ }^{5}$ suggesting that these cells have been preactivated in vivo. Even other mechanisms, such as the presence of inhibitory factors, have been proposed to explain low IL-2 production in vitro. ${ }^{21}$ We did not test whether the IL-2 present in the biopsy specimens was biologically active, but the demonstration of locally increased IL-2 concentrations in vivo seems to fit the recent demonstration that cyclosporin, a potent inhibitor of IL-2 production, has a beneficial therapeutic effect in patients with Crohn's disease ${ }^{22}$ and perhaps ulcerative colitis. ${ }^{23}$ 
The human IL-2R consists of a low affinity 55 $\mathrm{kDa} \alpha$ chain and an intermediate affinity $75 \mathrm{kDa}$ $\beta$ chain which form a dimeric, biologically active high affinity IL-2R complex. ${ }^{24-27}$ The $55 \mathrm{kDa} \alpha$ chain, previously known as the Tac receptor, is released/shed from activated $T$ cells in a soluble form, and Rubin et $a l^{28}$ devised an ELISA to determine sIL-2R as a marker of in vivo $T$ cell activation in biological fluids. Slightly increased in vitro $T$ cell surface expression of IL-2R have been previously shown in inflammatory bowel disease. ${ }^{6}$ The recent demonstration of substantially increased sIL-2R concentrations in serum, ${ }^{2-4}$ and now in mucosal inflammatory bowel disease biopsies indicate, however, that $\mathrm{T}$ cell activation also occurs in vivo in active inflammatory bowel disease. Soluble IL-2R binds free IL-2 and may even have a role at the gut level as a down regulator of $T$ cell functions by trapping free ligand. ${ }^{29}$

Taken together, the results of this study suggest that enhanced cellular immunity operate in vivo at the mucosal level in active inflammatory bowel disease.

The technical assistance of Birgit Deibjerg and Lene Person are cknowledged with great appreciation. Drs J Brynskov, N Tvede, and C B Andersen hold research fellowships granted by the University of Copenhagen, Faculty of Medicine.

1 Cantrell DA, Smith KA. The interleukin-2 T-cell system. Science 1984; 224: 1312-6.

2 Brynskov J, Tvede N. Plasma interleukin-2 and a soluble/shed interleukin-2 receptor in serum of patients with Crohn's disease. Effect of cyclosporin. Gut 1990; 31: 795-9.

3 Crabtree JE, Juby LD, Heatley RV, Lobo AJ, Bullimore DW, Axon ATR. Soluble interleukin-2 receptor in Crohn's disease: relation of serum concentrations to disease activity. Gut 1990; 31: 1033-6.

4 Mueller C, Knoflach P, Zielinski CC. T-cell activation in Crohn's disease. Increased levels of soluble interleukin-2 receptor in serum and in supernatants of stimulated peripheral blood mononuclear cells. Gastroenterology 1990; 98: 639-46.

5 Fiocchi C, Hilfiker ML, Youngman KR, Doerder NC, Finke $\mathrm{JH}$. Interleukin 2 activity of human intestinal mucosa mononuclear cells. Decreased levels in inflammatory bowel disease. Gastroenterology 1984; 86: 734-42.

6 Pallone F, Fais S, Squarcia O, Biancone L, Pozzilli P, Biorivant $M$. Activation of peripheral blood and intestinal lamina propria lymphocytes in Crohn's disease. Gut 1990; 28: 745-53.

7 Bendtzen K. Interleukin 1, interleukin 6 and tumour necrosis factor in infection, inflammation and immunity. Immunol Lett 1988; 19: 183-92.

8 Binder V, Both H, Hansen PK, Hendriksen C, Kreiner S, Torp-Pedersen $\mathrm{K}$. Incidence and prevalence of ulcerative colitis and Crohn's disease in the county of Copenhagen, 1962-1978. Gastroenterology 1982; 83: 563-8.
9 Malchow H, Ewe K, Brandes JW, et al. European Cooperative Crohn's Disease Study (ECCDS): results of drug treatment. Gastroenterology 1984; 86: 249-66.

10 Binder V. A comparison between clinical state, macroscopic and microscopic appearances of rectal mucosa and cytologic picture of mucosal exudate in ulcerative colitis. Scand $\mathcal{F}$ Gastroenterol 1970; 5: 627-32.

11 Harvey RF, Bradshaw JM. A simple index of Crohn's disease activity. Lancet 1980; i: 514.

12 Morson BC, Dawson IMP. Gastro-intestinal pathology. Oxford: Blackwell, 1979: 551-62.

13 Gaffney EW, Chu CW, Lingenfelter SE, Lisi PJ, Koch GA. Enzyme linked immunoassay with monoclonal antibody for human interleukin-1. Biotechniques 1987; 5: 652-6.

14 Siegel S, Castellan NJ. Nonparametric statistics for the behavioral sciences. 2nd ed. New York: McGraw-Hill, 1988: behavio

15 Gomes P, Du Boulay C, Smith CL, Holdstock G. Relationship between disease activity indices and colonoscopic findings in patients with colonic inflammatory bowel disease. Gut 1986; 27: $92-5$.

16 Fiocchi C. Cells of the gastrointestinal tract - isolation procedures. In: Pena AS, ed. Cells of the gastrointestinal tract. Isolation procedures and application in research. Acta Chir Scand 1990; (suppl 525): 11-24.

17 Ligumsky M, Simon PL, Karmeli F, Rachmilewitz D. Role of interleukin 1 in inflammatory bowel disease - enhanced production during active disease. Gut 1990; 31: 686-9.

18 Mahida YR, Wu K, Jewell DP. Enhanced production of interleukin $1 B$ by mononuclear cells isolated from mucosa interleukin $1 B$ by mononuclear cells isolated from mucosa with active

19 Bendtzen $\mathrm{K}$, Mandrup-Poulsen T, Nerup J, Nielsen JH, Dinarello CA, Svenson $M$. Human pI 7 interleukin 1 is cytotoxic for pancreatic islets of Langerhans. Science 1986; 232: 1545-7.

20 Rasmussen ÅK, Bech K, Feldt-Rasmussen U, Poulsen S, Holten I, Ryberg $M$, Dinarello CA, et al. Interleukin 1 affects the function of cultured human thyroid cells. Allergy 1988; 43: 435-41.

21 Myasaka N, Nakarama T, Russel IJ, Talal N. Interleukin 2 deficiencies in rheumatoid arthritis and systemic lupus deficiencies in rheumatoid arthritis and systemic lupus
erythematosus. Clin Immunol Immunopathol 1984; 31: 10917.

22 Brynskov J, Freund L, Nørby Rasmussen S, et al. A placebocontrolled, double-blind, randomized trial of cyclosporine therapy in active chronic Crohn's disease. $N$ Engl $\mathcal{F}$ Med 1989; 321: 845-50.

23 Lichtiger S, Present DH. Cyclosporin in treatment of severe active ulcerative colitis. Lancet 1990; 336: 16-9.

24 Tsudo M, Kozak RW, Goldman CK, Waldman TA. Demonstration of a non-Tac peptide that binds interleukin 2: a potential participant in multichain interleukin 2 receptor complex. Proc Natl Acad Sci 1986; 83: 9694-8.

25 Sharon M, Klausner RD, Cullen BR, Chizzonite R, Leonard WJ. Novel interleukin-2 receptor subunit detected by crosslinking under high-affinity conditions. Science 1986; 234: linking und

26 Teshigawara $\mathrm{K}$, Wang $\mathbf{H}$, Kato $\mathrm{K}$, Smith KA. Interleukin 2 high-affinity receptor expression requires two distinct binding proteins. F Exp Med 1986; 165: 223-38.

27 Fujii M, Sogamura K, Sabno K, Nakai M, Sugita K, Hinuma $Y$. High-affinity receptor-mediated internalization and degradation of interleukin 2 in human T-cells. $\mathcal{F}$ Exp Med 1986; 163: 550-62.

28 Rubin LA, Kurman CC, Fritz ME, et al. Soluble interleukin 2 receptors are released from activated human lymphoid cells in vitro. F Immunol 1985; 135: 3172-7.

29 Rubin LA, Jay G, Nelson DL. The released interleukin 2 receptor binds interleukin 2 efficiently. F Immunol 1986; 137: $3841-4$. 